\title{
Numerical simulations of infected-grain detection based on laser- ultrasonic technique
}

\author{
Fan Chao, Jiao Ya-jie and Song Yu-pei \\ College of the Information Science and Engineering, Henan University of \\ Technology, 450001 Zhengzhou, China
}

Received: 06.06.2019

\begin{abstract}
When a wheat kernel is infected by insects, nutrients of the kernel are damaged, which reduces the commercial value of wheat and threatens its food safety. We suggest a new non-destructive method for revealing infected kernels, which is based on laser-induced ultrasonic. A detection process is simulated using a finite-element analysis. Firstly, we formulate a finite-element model for normal wheat and models for infected wheat (with the wormhole radii $0.4,0.6,0.8$ and $1.0 \mathrm{~mm}$ ), following from a classical thermal-stress theory. Secondly, a controlling equation is obtained, a process of ultrasonic excitation is simulated for all the models using a standard Newmark time-integration method, and the ultrasonic signals are obtained for those models. Finally, we derive the velocity of ultrasonic wave propagating in the kernel and analyze the relationships among the ultrasonic parameters and the structural parameters of the models. Our results show that the time interval between two adjacent ultrasonic echoes depends notably upon the internal kernel structure. In particular, the interval between the first and second echoes is longer and the interval between the second and third echoes is shorter with increasing wormhole radius. This can be used for finding out the infected kernels at early stages and determining the sizes of wormholes.
\end{abstract}

Keywords: infected grain, laser ultrasound, detection methods, finite-element analysis

UDC: $535+534.14$

\section{Introduction}

Wheat kernels are easily infected by insects when they are stored without proper processing. This affects the quality of grain itself and its products [1]. Therefore, early detection of infected kernels is very important for keeping high-quality wheat and reducing post-harvest losses. A common method for detecting infected grain is based mainly on the difference in density and suspension speed between the infected and normal kernels. The method is time-consuming and laborious. Often, it fails to distinguish infected kernels because of some unaccounted factors, while the testing accuracy can be unsatisfactory [2]. In the recent years, a number of new testing methods have been suggested, e.g. those based on acoustics [3], near-infrared spectroscopy [4] and X-ray studies [5]. Although these methods can overcome many drawbacks of the common detection method, they have restrictions of their own.

Let us mention some illustrations. The acoustic method can detect the infected kernels basing on the acoustic signal produced when a kernel hits a metal target. The reason is that there are wormholes or insect tunnels inside the infected kernels, which cause changes in their internal structure. The weight of a kernel becomes less and, hence, the sound signal is different. Although the infected kernels can be detected fast, the method is affected by the background noise that appears in the microphone used for acquiring the sonic signal. The near-infrared spectroscopy can 
detect the infected grain since there is a difference in the absorption or reflection of the nearinfrared electromagnetic waves for the cases of infected and normal wheat. However, it is impossible to detect the infection in its egg-larval stage. Moreover, the method is easily affected by the content of grain moisture and cannot detect dead insects. The other method uses X-rays to penetrate a kernel. Then ionized atoms produce fluorescence such that the grain can be imaged. However, it is difficult to detect tiny larvae or eggs and, moreover, the method cannot be used as long-term and large-scale because of its radiation risks [6].

To recognize the infected wheat kernel at early stages, a new real-time non-destructive detection method based on the laser-induced ultrasonic has been put forward [7]. Here the detected ultrasonic signal is obtained and processed in the both time and frequency domains, using fast Fourier transform and discrete cosine transform. Six significant features have been selected as the characteristic parameters of signals, using a method of stepwise discriminant analysis. Then, a back-propagation neural network has been designed using these six parameters as an input, in order to distinguish the infected kernels from the normal ones. The results have demonstrated that the infected kernels can be recognized efficiently, whereas the false negative and false positive errors are only $12 \%$ and $9 \%$, respectively. Although the discriminant method based on the erosion effect of laser ultrasonics has already been studied well, this does not concern the excitation process of the ultrasonic signal. Moreover, the propagation velocity of the ultrasound has also not been measured and the relationships between the signal characteristics and the parameters of infected kernels (especially the wormhole sizes) have not been revealed. Unfortunately, all of those problems are difficult to study basing solely on experiments. The propagation process and the velocity of ultrasonic waves in the kernel should rather be simulated numerically and the relationships among the signal parameters and the sizes of wormholes can be analyzed using a finite-element method.

In the present work, we first give the principles of measurements for the infected kernels, following from the laser ultrasonics, the classical heat-transfer theory and the wave equation. Then a normal model and four infected models with different erosion radii are introduced and simulated ultrasonic signals are excited using the finite-element method. Finally, we analyze the propagation process and its velocity, and study the relationships among the characteristics of ultrasonic signals and infected kernels.

\section{Principles of laser-ultrasonic detection of infected kernels}

Laser light has been widely studied and applied in various fields, e.g. in information science and telecommunications, medical diagnostics and treatment, industry, military technologies and hardness detection of wheat [8-13]. When an object is irradiated by laser, the laser energy is quickly absorbed and heat is generated. This creates large thermal gradients near the object surfaces and results in thermal expansion [14-16]. Then a certain stress distribution is generated and ultrasonic waves are excited. We have an ultrasound excited due to a thermo-elastic effect. Being widely used for non-destructive detection in many fields, it has been studied extensively [17-19]. In the recent years, numerical simulations of laser-ultrasonic propagation have been developed rapidly, using the finite-element method. The method is capable of simulating soundfield distributions and describing with high accuracy the displacement waveform observed at any point $[20,21]$.

In Fig. 1 we illustrate a situation when a surface of wheat kernel is irradiated by a pulsed laser. The laser energy is absorbed and the surface temperature of wheat kernel increases rapidly, 
resulting in uneven distribution of temperature field. Due to thermo-elastic coupling, a mechanical motion is excited as a result of constraints appearing among the adjacent particles of kernel. In this manner the ultrasonic waves are excited and propagate outward.

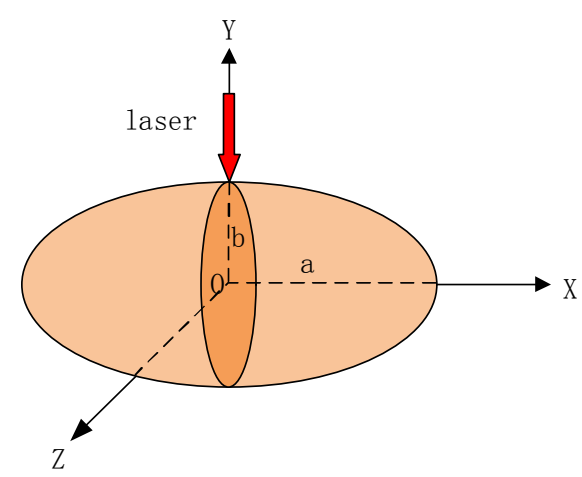

Fig. 1. Scheme of irradiation of wheat kernel with laser light.

Issuing from the energy conservation law, the enthalpy of grain surface increases whenever the grain is irradiated by the pulsed laser. Macroscopically this can be represented as temperature increase and volume expansion. During energy exchange between the laser and the kernel, the convection and radiation effects are not considered, so that heat conduction is considered as the main process. Assuming the Gaussian distribution of pulsed-laser characteristics, one can write the heat conduction equation as

$$
\rho \mathrm{c} \frac{\partial T(x, y, z, t)}{\partial t}=\frac{\partial}{\partial x}\left(k_{x} \frac{\partial T(x, y, z, t)}{\partial x}\right)+\frac{\partial}{\partial y}\left(k_{y} \frac{\partial T(x, y, z, t)}{\partial y}\right)+\frac{\partial}{\partial z}\left(k_{z} \frac{\partial T(x, y, z, t)}{\partial z}\right),
$$

where $T(x, y, z, t)$ denotes the temperature distribution at a time $t$, the parameters $\rho, c$ and $k$ imply respectively the density, the heat capacity and the thermal conductivity coefficient of wheat.

The availability of pulsed laser can be regarded as a kind of boundary conditions with respect to the wheat kernel. Here we deal in fact with an external heat source of which the energy and distribution changes over time. Since the boundary condition for the heat flow must be satisfied in the irradiated region which is situated on the upper surface of the kernel, we have

$$
-\left.K_{y} \frac{\partial T(x, y, z, t)}{\partial y}\right|_{y=b}=I_{0} A(T) f(r) g(t) .
$$

At the same time, the adiabatic condition is satisfied on the lower surface of the kernel:

$$
\frac{T(x, y, z, t)}{y}=0, y=-b,
$$

where $A(T)$ is the absorption rate of the wheat, $b$ the radius of cross section of the kernel model, $I_{0}$ the energy of pulsed laser, and $f(r)$ and $g(t)$ represent the spatial and temporal distribution functions for the laser pulse. The latter can be expressed as

$$
\begin{aligned}
& f(r)=\exp \left(-r^{2} / a_{0}^{2}\right), \\
& g(t)=\frac{t}{t_{0}^{2}} \exp \left(-\frac{t}{t_{0}}\right),
\end{aligned}
$$

where $r$ is the distance of the point of measurements from the laser centre, $a_{0}$ the spot radius of the laser irradiation, and $t_{0}$ the rise time of the pulsed laser. 
Although the time of laser action is very short, its power is high. Then the effect of thermostructural coupling affects significantly the characteristics of generated ultrasonic signal. When the laser power is lower than the melting threshold of the kernel, local thermal expansion occurs near the kernel surface. The transient displacement thus excited satisfies the following equation:

$$
(\lambda+2 \mu) \nabla(\nabla \times \vec{U})-\mu(\nabla \times \nabla \times \vec{U})-\alpha(3 \lambda+2 \mu) \nabla T(x, y, z, t)=\rho \frac{\partial^{2} T}{\partial t^{2}}
$$

where $\vec{U}$ is the transient displacement, $\lambda$ and $\mu$ are the Lame constants of the wheat, and $\alpha$ and $\rho$ denote the thermal expansion coefficient and the density of wheat, respectively.

Free boundary conditions should be met on the upper and lower surfaces of the kernel that correspond to $y=b$ and $y=-b$ :

$$
\vec{n} \times \sigma=0,
$$

where $\vec{n}$ is the unit vector of the vertical surface and $\sigma$ the stress tensor. Meanwhile, the following initial condition is satisfied:

$$
\vec{U}(x, y, z, t)=\frac{\partial \vec{U}(x, y, z, t)}{\partial t}=0, \quad t=0,
$$

\section{Numerical simulations with finite-element method}

To study the processes of laser-induced ultrasonic excitation and propagation, we have employed the finite-element method. Here the wheat is regarded as an idealized isotropic uniform medium. Let the laser light be incident along the negative direction of $y$-axis. We suggest a 'one-half solid model', which is symmetric with respect $y z$ plane. The pulsed laser supplies instantaneous heat for the kernel and the thermal stresses are analyzed by indirect coupling method. We use an 8-node 3D thermal solid element to analyze the transient thermal process. An equivalent structural element is adopted for the structural analysis. According to the principle of virtual work, the finiteelement control equation is as follows:

$$
[M]\{\ddot{\vec{U}}\}+[K]\{\vec{U}\}=\left\{\vec{F}_{\text {laser }}\right\},
$$

where $[M]$ is the mass matrix, $[K]$ the stiffness matrix, $\vec{U}$ the displacement vector, $\ddot{\vec{U}}$ the acceleration vector, and $\vec{F}_{\text {laser }}$ the laser-induced transient-force source generated around the irradiated area of kernel. The kernel can be regarded as a thermal elastic body. In the cylindrical coordinate system, the external-force vector is expressed as $\int[B]^{\mathrm{T}}[D]\left\{\varepsilon_{0}\right\} d V$, where $\left\{\varepsilon_{0}\right\}$ denotes the thermal-strain vector, $[B]^{\mathrm{T}}$ the transposed matrix of multiplicative inverse of the shape function, and $[D]$ the tissue property matrix of wheat.

Eq. (9) is based on the balance equation with the time $t$. To obtain the time-history curve of displacement, the equation must be discretized in the time domain and solved with a standard Newmark time-integration method. Supposing that the time step is given by $\Delta t$, one can write the displacement and its first derivative as

$$
\begin{aligned}
& \{\dot{\vec{U}}\}_{t+\Delta t}=\{\dot{\vec{U}}\}_{t}+\left[(1-\gamma)\{\ddot{\vec{U}}\}_{t}+\gamma\{\dot{\vec{U}}\}_{t+\Delta t}\right] \Delta t, \\
& \{\vec{U}\}_{t+\Delta t}=\{\vec{U}\}_{t}+\Delta t\{\dot{\vec{U}}\}_{t}+\left[(0.5-\beta)\{\ddot{\vec{U}}\}_{t}+\beta\{\ddot{\vec{U}}\}_{t+\Delta t}\right] \Delta t^{2},
\end{aligned}
$$

where $\beta$ implies the parameter that determines stability of the integral and $\gamma$ the parameter that determines its accuracy. 
Substituting Eqs. (10) and (11) into Eq. (9), one obtains

$$
a_{0}=\frac{1}{\beta \Delta t^{2}}, a_{1}=\frac{\gamma}{\beta \Delta t}, a_{2}=\frac{1}{\beta \Delta t}, a_{3}=\frac{1}{2 \beta}-1, a_{4}=\frac{\gamma}{\beta}-1, a_{5}=\frac{\Delta t}{2}\left(\frac{\gamma}{\beta}-2\right),
$$

Here the notations

$$
a_{0}=\frac{1}{\beta \Delta t^{2}}, a_{1}=\frac{\gamma}{\beta \Delta t}, a_{2}=\frac{1}{\beta \Delta t}, a_{3}=\frac{1}{2 \beta}-1, a_{4}=\frac{\gamma}{\beta}-1, a_{5}=\frac{\Delta t}{2}\left(\frac{\gamma}{\beta}-2\right),
$$

are used, with $[C]$ being the heat capacity matrix of wheat. In this way, the time history curve for the entire displacement field can be generated by continuous integration.

\section{Simulation results and their analysis}

Five different models are introduced in this study. These are a normal-wheat model (model 1) and four infected-wheat models with the wormhole radii $0.4,0.6,0.8$ and $1.0 \mathrm{~mm}$ (models 2 to 5 , respectively). The wormhole is regarded as a sphere of which central point is located at the origin. The kernel is modelled as an ellipsoid, of which long and short axes are equal respectively to $a=3 \mathrm{~mm}$ and $b=1.5 \mathrm{~mm}$. The physical parameters of wheat used in our numerical simulations are listed in Table 1.

Table 1. Some physical parameters of wheat needed for our simulations.

\begin{tabular}{cccccc}
\hline $\begin{array}{c}\text { Density, } \\
\mathrm{kg} / \mathrm{m}^{3}\end{array}$ & $\begin{array}{c}\text { Thermal } \\
\text { conductivity, } \\
\mathrm{W} /(\mathrm{m} \times \mathrm{K})\end{array}$ & $\begin{array}{c}\text { Specific heat } \\
\text { capacity, } \\
\mathrm{J} /(\mathrm{kg} \times \mathrm{K})\end{array}$ & $\begin{array}{c}\text { Linear thermal } \\
\text { expansion coefficient, } \\
\mathrm{K}^{-1}\end{array}$ & $\begin{array}{c}\text { Elastic } \\
\text { modulus, } \\
\mathrm{Pa}\end{array}$ & $\begin{array}{c}\text { Poisson } \\
\text { ratio }\end{array}$ \\
\hline 760 & 0.15 & 0.32 & $1 \times 10^{-10}$ & $3 \times 10^{8}$ & 0.3 \\
\hline
\end{tabular}

When the laser irradiates the kernel, heat conduction is considered as the main physical process, which results in a sharp temperature increase near the kernel surface. The convective and radiative effects are ignored. The mesh size of the finite element is taken to be $200 \mu \mathrm{m}$, the initial temperature for all of the five models and the reference temperature of the thermal stress are both equal to $25^{\circ} \mathrm{C}$. The power density of the Gaussian laser beam amounts to $3 \times 10^{12} \mathrm{~W} / \mathrm{m}^{2}$ and the pulse width to $0.1 \mu \mathrm{s}$.

Fig. 2 shows simulation flow chart for our thermal-stress analysis of laser ultrasonic based on the finite-element analysis. The transient thermal processes are analyzed by defining two load steps. In the first load step, we simulate in fact the action of pulsed laser. Here the duration is equal to $1 \times 10^{-7} \mathrm{~s}$ and the time step is $1 \times 10^{-8} \mathrm{~s}$. In the second load step, the body load is deleted because the irradiation of the pulsed laser has already been finished. Here the variations of temperature field are simulated, with the same time step equal to $1 \times 10^{-8} \mathrm{~s}$. Then the structural analysis is performed. Its results for the transient thermal process are applied as a body load in order to find the displacement field.

When the grain is irradiated by the laser, the energy of the latter is absorbed in a rim surface zone of the kernel and the temperature is increasing sharply, thus forming large thermal gradient and causing thermal expansion near the surface layer. A stress distribution is generated due to constraints of surrounding tissues of the grain. In Fig. 3, the transient thermal stress distribution along the $y$ direction is shown for the normal kernel and the infected kernel with the radius $0.8 \mathrm{~mm}$. One can see that the maximal compressive stresses for the normal and infected kernels are equal respectively to 43.20 and $38.39 \mathrm{KPa}$. They are located near the irradiation point. The stress becomes smaller farther apart from this point. When the wheat is infected, there appears a hole Ukr. J. Phys. Opt. 2019, Volume 20, Issue 3 
filled with air inside the kernel. Considering that the density of air is much less than that of the wheat, one concludes that the compressive stress is buffered and attenuated. This causes the stress in the infected kernel to be weaker if compared with that typical for the normal kernel.

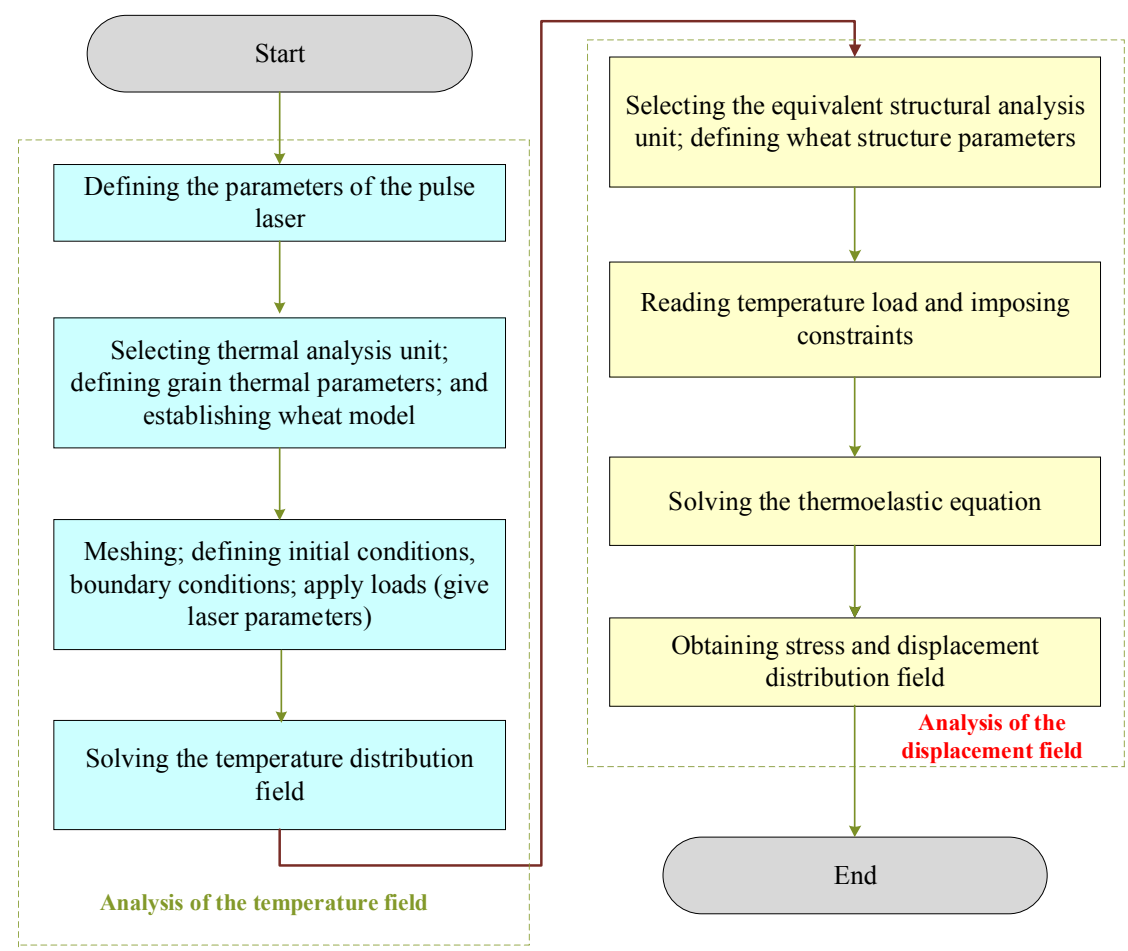

Fig. 2. Flow chart for our analysis of thermo-structural coupling.

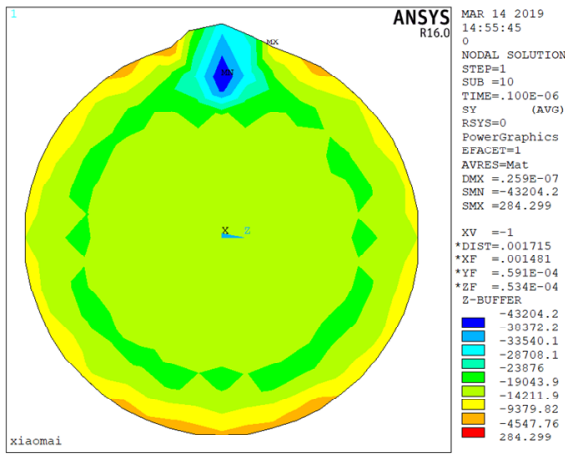

(a)

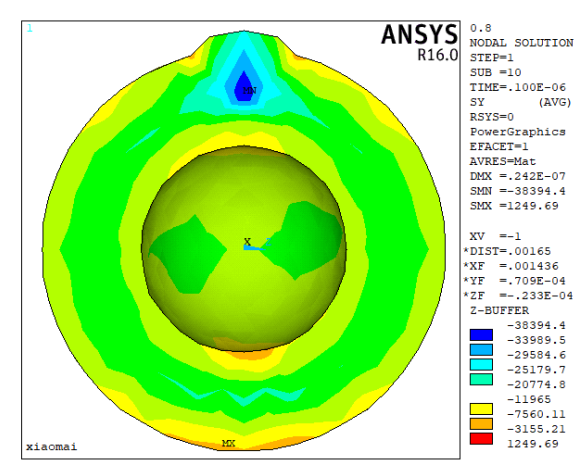

(b)

Fig. 3. Stress-field distributions obtained for normal (a) and infected (b) kernels. The hole radius for the latter is equal to $0.8 \mathrm{~mm}$.

The absorbed laser power causes non-uniformity of the temperature along the radial and axial directions, which excites the stresses along these directions. To detect the infected kernels, we analyze just the radial stress for all of our models. The propagation of the excited ultrasonic along the $y$ axis is illustrated in Fig. 4. Here the laser light is incident parallel to the $y$ axis and the irradiated point is denoted as A (the coordinates $(0 \mathrm{~mm} ; 1.5 \mathrm{~mm})$ ). The point of detection is the same point A. For the normal wheat, the laser-induced ultrasonic propagates inside the kernel and is then reflected at the bottom boundary. The first reflected signal, which reaches the detection 


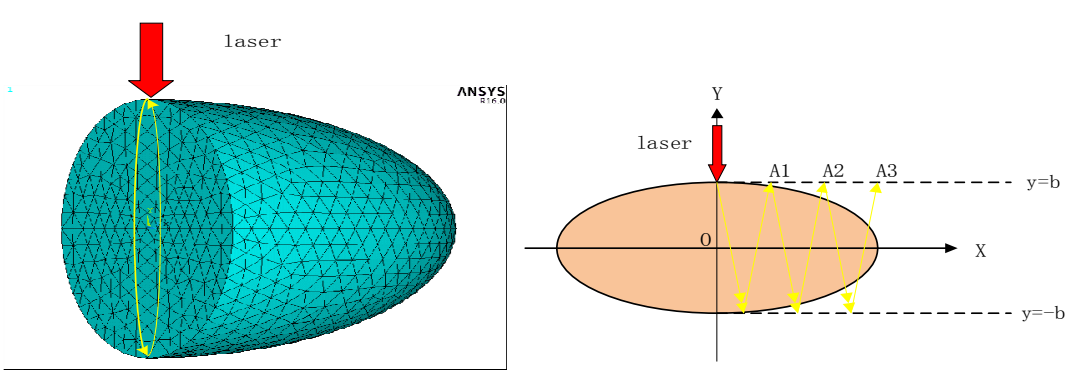

(a)

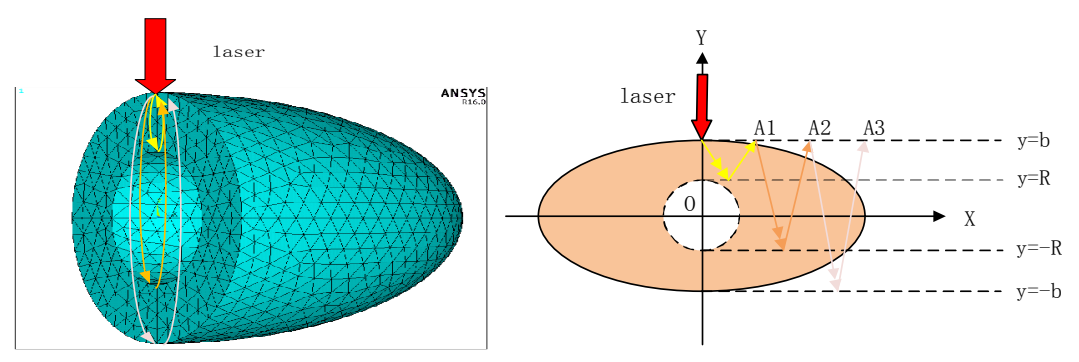

(b)

Fig. 4. Schematic diagrams of ultrasonic propagation in normal (a) and worm-eaten (b) wheat kernels.

point $\mathrm{A}$, is recorded as $\mathrm{A} 1$. Then a part of the signal is reflected again and again between the upper and bottom bounds of the kernel. The appropriate signals received at the point $\mathrm{A}$ are denoted as A2, A3, ... (see Fig. 4a). Since there is a hole inside the infected kernel, a part of the ultrasonic is first reflected at the upper and lower boundary of the hole, which corresponds to the locations $y=R$ and $y=-R$. The signals received at the detection point $\mathrm{A}$ are denoted as $\mathrm{A} 1$ and $\mathrm{A} 2$. Then a part of the ultrasonic signal penetrates the hole and reaches the bottom of the kernel. It is reflected and detected at the point A (see the signal A3 in Fig. 4b).

The signal waveforms detected at the point $\mathrm{A}$ for the cases of all five models are shown in Fig. 5a. Two or more extreme points can be obtained for each of the models, because multiple reflections at the boundaries of the kernel occur at different times. In order to understand better the propagation of ultrasonic mode inside the wheat, one has to analyze the signals for each of the models.

The ultrasonic signal obtained for the normal wheat is shown in Fig. $5 \mathrm{~b}$. The point A1 is the first maximum at the detection point corresponding to the first reflection, with the arrival time being equal to $t_{1}=2.63 \times 10^{-6} \mathrm{~s}$. The maximum point $\mathrm{A} 2$ is associated with the second reflection detected at the time $t_{2}=7.75 \times 10^{-6} \mathrm{~s}$. Finally, the point $\mathrm{A} 3$ corresponds to the third echo signal received at the time $t_{3}=1.316 \times 10^{-5} \mathrm{~s}$. The intervals between the two adjacent reflected signals are $\Delta t_{1}=t_{2}-t_{1}=5.12 \times 10^{-6}$ and $\Delta t_{2}=t_{3}-t_{2}=5.41 \times 10^{-6} \mathrm{~s}$. Then the average interval is equal to $\Delta t=\left(\Delta t_{1}+\Delta t_{2}\right) / 2=5.27 \times 10^{-6} \mathrm{~s}$. According to the trivial formula $V=S / t$, the propagation speed of the ultrasonic wave in the normal wheat amounts to $V=1139.6 \mathrm{~m} / \mathrm{s}$.

The ultrasonic signal detected along the $y$ axis for the model 2 is shown in Fig. $5 \mathrm{c}$. The first three reflected signals detected at the point $\mathrm{A}$ are denoted as A1, A2 and A3. The corresponding arrival times are $t_{1}=3.43 \times 10^{-6}, t_{2}=8.13 \times 10^{-6}$ and $t_{3}=1.048 \times 10^{-5} \mathrm{~s}$, respectively. According to Fig. $4 \mathrm{~b}$, the first and second reflections of the ultrasonic wave occur at the top and bottom boundary of the hole, so that the path length difference for these two signals is twice the wormhole 


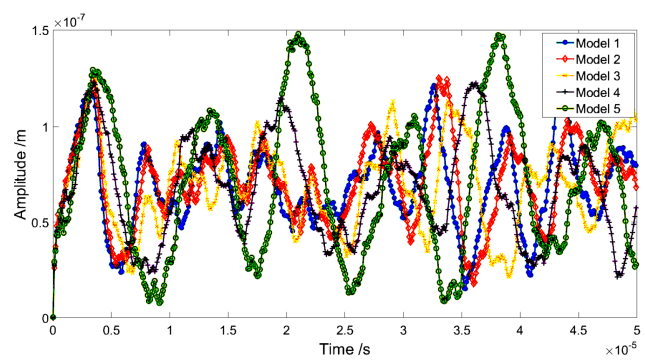

(a)

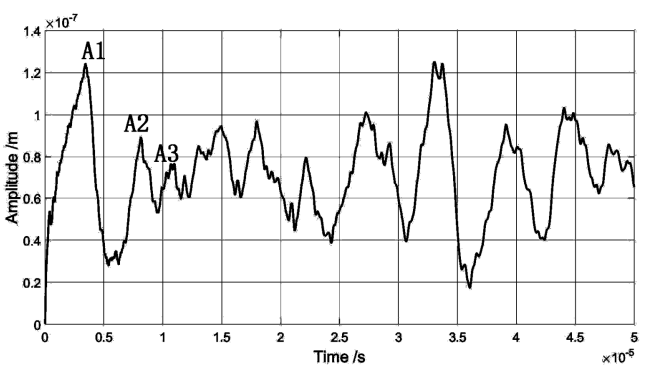

(c)

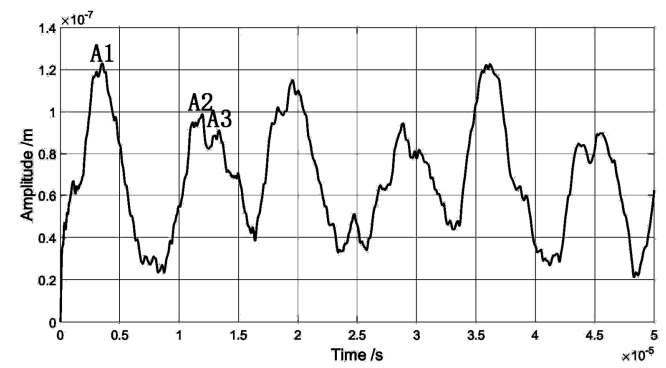

(e)

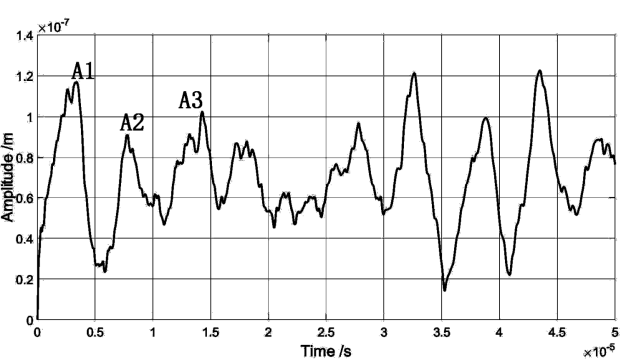

(b)

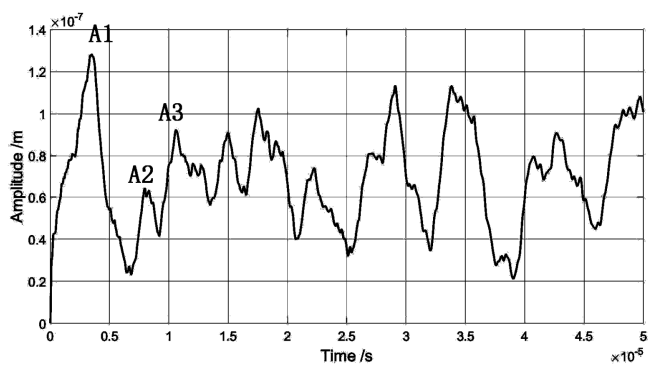

(d)

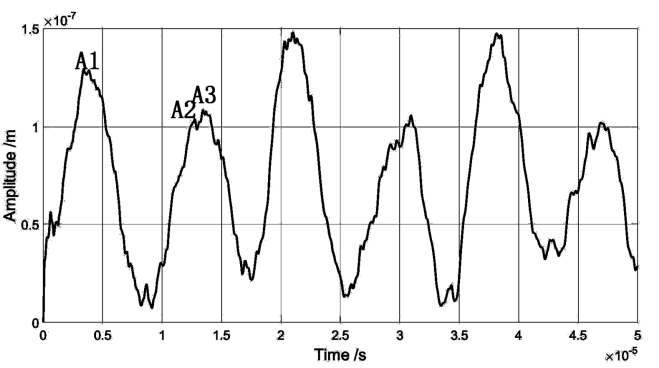

(f)

Fig. 5. Comparison of ultrasonic-signal waveforms simulated for different wheat models (a), and particular signals simulated for the models 1 (b), 2 (c), 3 (d), 4 (e) and 5 (f).

diameter, and the interval is equal to $\Delta t_{1}=t_{2}-t_{1}=4.7 \times 10^{-6} \mathrm{~s}$. Hence, the hole radius $R$ can be calculated as $R=V_{0} \Delta t_{1} / 4$, where $V_{0}$ denotes the ultrasonic speed in air ( $\left.V_{0} \approx 340 \mathrm{~m} / \mathrm{s}\right)$. We obtain the hole radius $R=0.400 \mathrm{~mm}$ and the error $\Delta R=0.001 \mathrm{~mm}$. Similarly, the path length difference between the second and third echo signals is twice the thickness of the kernel underneath the wormhole. Since the time interval between the two signals is equal to $\Delta t_{2}=t_{3}-t_{2}=2.35 \times 10^{-6} \mathrm{~s}$, the thickness underneath the hole is given by $b-R=V \Delta t_{2} / 2$, where the $V$ parameter has been calculated above. We obtain $b-R=1.34 \mathrm{~mm}$ and the absolute error $|\Delta(b-R)|=0.24 \mathrm{~mm}$. Finally, the radii of the wormholes and the thicknesses of the kernels underneath the holes for the models 3, 4 and 5 can be calculated in the same way. The relevant results are gathered in Table 2 .

Basing on the above results, one can see that the arrival time and the amplitude of the reflected signals depend on the wormhole radius. The underlying reason is that, when the energy of the pulsed laser is absorbed by the infected kernel, the distribution and diffusion of the temperature field become different, if compared with the normal kernel, thus resulting in changed ultrasonic velocity. The time taken by the ultrasonic to pass the hole increases with increasing wormhole radius, which causes the interval between the first and second echoes to be longer. 
The thickness of the layer between the hole and the surface of the kernel becomes less whenever the wormhole radius becomes larger. Then the propagation time of the ultrasonic in the kernel decreases, leading to shorter intervals between the second and third reflected signals.

Table 2. Time intervals and some geometrical parameters calculated from the ultrasonic-signal waveforms for different models of wheat kernel.

\begin{tabular}{ccccccc}
\hline Model & $\begin{array}{c}\Delta t_{1}, \\
10^{-6} \mathrm{~s}\end{array}$ & $\begin{array}{c}R, \\
\mathrm{~mm}\end{array}$ & $\begin{array}{c}\Delta R, \\
\mathrm{~mm}\end{array}$ & $\begin{array}{c}\Delta t_{2}, \\
\mathrm{~s}\end{array}$ & $\begin{array}{c}b-R, \\
\mathrm{~mm}\end{array}$ & $\begin{array}{c}\Delta(b-R), \\
\mathrm{mm}\end{array}$ \\
\hline 2 & 4.700 & 0.3995 & 0.0005 & $2.35 \times 10^{-6}$ & 1.3400 & 0.2400 \\
3 & 7.090 & 0.6027 & 0.0027 & $1.92 \times 10^{-6}$ & 1.0940 & 0.1940 \\
4 & 8.910 & 0.7574 & 0.0426 & $1.41 \times 10^{-6}$ & 0.8034 & 0.1034 \\
5 & 1.101 & 0.9359 & 0.0642 & $1.09 \times 10^{-6}$ & 0.6211 & 0.1211 \\
\hline
\end{tabular}

Hence, a number of important physical parameters of wheat can be inferred issuing from the parameters of the laser-induced ultrasonic signal. In particular, the analysis of the detected echo signals can resolve the problem of whether the kernel is infected or not, as well as yield the size and the position of the wormhole. This implies that the infected kernels can be recognized and studied at the early infection stages, using the laser-ultrasonic technique.

\section{Conclusion}

The mechanical displacement field generated by the pulsed laser is simulated for the normal and infected wheat kernels, using the finite-element method. It is revealed that the propagation velocities of ultrasonic signal are different for the cases of normal and infected kernels, because the physical parameters of the kernel are changed by the wormholes. The interval between the two adjacent echo signals is almost invariable for the normal kernels. On the other hand, the ultrasonic wave suffers extra reflections at additional boundaries appearing inside the infected kernels, thus causing the intervals and the amplitudes of the detected signal to become essentially different, if compared to the case of normal kernels. All of these differences are closely related to the geometry of wormholes. The propagation of the laser-induced ultrasonic is simulated for a number of wheat models. It is demonstrated that the infected kernels can be successfully distinguished from the normal ones and the radii of the wormholes can be measured, following from the time intervals among different reflected ultrasonic signals. This suggests a new method for detecting the fact of wheat infection at its early stages.

\section{Acknowledgments}

This work has been a part of the project supported by the Natural Science Foundation of Henan Province (No. 162300410062), the Science and Technology Support Project from the State Grain Administration (No. 201413001), the China Scholarship Council (No. 201408410255), and the Key Laboratory of the Grain Information Processing and Control of Ministry of Education of China (No. KFJJ-2017-106).

\section{References}

1. Zhihui Li, Tong Zhen, Yuhua Zhu, 2019. Research on time series modeling in grain storage hidden insects environment detection. Ekoloji, 28: 4521-4525.

2. Neethirajan S, Karunakaran C, Jayas DS, White NDG, 2007. Detection techniques for storedproduct insects in grain. Food Control. 18: 157-162. 
3. Eliopoulos PA, Potamitis I, Kontodimas DCh, Givropoulou EG, 2015. Detection of adult beetles inside the stored wheat mass based on their acoustic emissions. J. Econom. Entomol. 108: $2808-2814$.

4. Chelladurai V, Karuppiah K, Jayas D S, Fields PG, White NDG, 2014. Detection of Callosobruchus maculatus (F.) infestation in soybean using soft X-ray and NIR hyperspectral imaging techniques. J. Stored Prod. Res. 57: 43-48.

5. Boniecki P, Piekarska B H, Swierczynski K, Koszela K, Zaborowicz M, Przybył J, 2014. Detection of the granary weevil based on X-ray images of damaged wheat kernels. J. Stored Prod. Res. 56: 38-42.

6. Km Sheetal Banga, Nachiket Kotwaliwale, Debabandya Mohapatra, Saroj Kumar Giri, 2019. Techniques for insect detection in stored food grains: an overview. Food Control. 97: 115116.

7. Chao Fan, 2015. Early discriminant method of infected kernel based on the erosion effects of laser ultrasonics. Laser Phys. 25: 076101.

8. Li J Y, Niu H S and Niu Y X, 2017. Laser feedback interferometry and applications: a review. Opt. Eng. 56: 050901.

9. Nemets $\mathrm{M}$ and Pastor A A, 2017. Lasers in analysis: potential and prospects for the development of ultrashort pulsed lasers. Rus. J. Phys. Chem. B. 11: 95-98.

10. Padmanabham $G$ and Bathe R, 2018. Laser materials processing for industrial applications. Proc. Nat. Acad. Sci. 88: 359-374.

11. Dawood M S, 2016. The effects of ultrasound and alternating current on the laser penetration in the tissue. Las. Med. Sci. 31: 955-964.

12. Chao Fan, Jing-bo Xu, Tie-jun Yang and Hong-Liang Fu, 2014. Research on a measurement method for wheat hardness based on the erosion effects of laser ultrasonics. Laser Phys. 24: 046101.

13. Fan Chao. 2017. Detection of wheat hardness based on a laser-generated ultrasonic signal. Ukr. J. Phys. Opt. 18: 201-212.

14. Urzova $\mathrm{J}$ and Jelinek M, 2018. Heat transfer modelling of pulsed laser-tissue interaction. Laser Phys. 28: 036001.

15. LuisPolo-Parada, Gerardo Gutiérrez-Juárez, Jennifer A Kist, Laxmi Adhikari, Nakara Bhawawet, Gary A.Baker, 2019. Laser-induced sound pinging (LISP): A rapid photoacoustic method to determine the speed of sound in microliter fluid volumes. Sensors and Actuators B - Chemical. 291: 401-410.

16. Popovich A A, Masaylo D V, Sufiiarov S, Borisov E V, Polozov I A, Bychenok V A, Kinzhagulov I Yu, Berkutov I V, Ashikhin D S, Il'inskii A V, 2016. A laser ultrasonic technique for studying the properties of products manufactured by additive technologies. Rus. J. Nondestruct. Testing. 52: 303-309.

17. Hossam Selim, Miguel Delgado Prieto, José Trull, Luis Romeral, and Crina Cojocaru, 2019. Laser ultrasound inspection based on wavelet transform and data clustering for defect estimation in metallic samples. Sensors. 19: 573.

18. Sedaghati A, Honarvar F and Sinclair A N, 2019. Lamb wave-based experimental and numerical studies for detection and sizing of corrosion damage in metallic plates. Proc. Inst. Mech. Eng., Part C - J. Mech. Eng. Sci. 233: 2107-2120.

19. Ziming Li, Cunfu He, Zenghua Liu, BinWu , 2019. Quantitative detection of lamination defect in thin-walled metallic pipe by using circumferential Lamb waves based on wavenumber analysis method. NDT \& E International. 102: 56-67. 
20. Wei Zeng, Shikai Qi, Li Liu, Yeiyan Yao, 2019. Research on laser-generated Rayleigh waves with angled surface crack by finite element method. Optik. 181: 57-62.

21. Yu Zhan, Changsheng Liu, Xiangwei Kong, Yingmei Li, 2018. Measurement of fiber reinforced composite engineering constants with laser ultrasonic. Appl. Acoust. 139: 182-188.

Fan Chao, Jiao Ya-jie and Song Yu-pei. 2019. Numerical simulations of infected-grain detection based on laser-ultrasonic technique. Ukr.J.Phys.Opt. 20: 113 - 123.

doi: $10.3116 / 16091833 / 20 / 3 / 113 / 2019$

Анотація. Коли пшеничне зерно заражене комахами, пошкодження його поживних речовин понижує комериійну иінність пшенииі $i$ загрожує безпеиі иьього харчового продукту. Ми пропонусмо новий неруйнівний метод виявлення інфікованих зерен, заснований на лазерноіндукованому ультразвукові. Прочес виявлення моделюється на основі методу скінченних елементів. Спочатку сформульовано модель скінченних елементів для нормальної пиенииі та моделі опису інфікованої пшенииі (з радіусами червоточини 0,4, 0,6, 0,8 i 1,0 мм), виходячи з класичної теорії термічного стресу. Далі одержано керуюче рівняння, промодельовано процес збудження ультразвуку для всіх моделей із використанням стандартного методу часового інтегрування Ньюмарка, а також одержано ультразвукові сигнали для иих моделей. Нарешті, знайдено швидкість ультразвукової хвилі, яка поширюється в зерні, і проаналізовано співвідношення між ультразвуковими параметрами i структурними параметрами моделей. Намі результати засвідчують, що часовий інтервал між двома сусідніми ультразвуковими луна-сигналами помітно залежить від внутрішньої структури зерна. Зокрема, інтервал між першим і другим луна-сигналами довший, а інтервал між другим і третім луна-сигналами коротший у разі більшого радіуса червоточини. Це можна використати для виявлення заражених зерен на ранніх стадіях зараження та для визначення розмірів червоточин. 